\title{
The addition of high magnifying endoscopy improves rates of high confidence optical diagnosis of colorectal polyps
}

Authors

Institutions
Mineo Iwatate ${ }^{1}$, Yasushi Sano ${ }^{1}$, Santa Hattori ${ }^{1}$, Wataru Sano' ${ }^{1}$, Noriaki Hasuike ${ }^{1}$, Taro Ikumoto ${ }^{1}$, Masahito Kotaka', Yoshitaka Murakami ${ }^{2}$, David G. Hewett ${ }^{3}$, Roy Soetikno ${ }^{4}$, Tonya Kaltenbach ${ }^{4}$, Takahiro Fujimori ${ }^{5}$

Institutions are listed at the end of article.

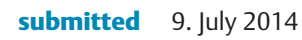
accepted after revision 5. December 2014

\section{Bibliography}

DOI http://dx.doi.org/

10.1055/s-0034-1391362

Published online: 17.2.2015

Endoscopy International Open 2015; 03: E140-E145

(c) Georg Thieme Verlag KG Stuttgart · New York

E-ISSN 2196-9736

\section{Corresponding author}

\section{Mineo Iwatate, MD}

Gastrointestinal Center,

Endoscopy

Sano Hospital

2-5-1 Shimizugaoko

Tarumi Ward, Kobe

Hyogo Prefecture 6550031

Japan

Fax: 0787850077

m.iwatate15@gmail.com
Background and study aims: The real-time optical diagnosis of colorectal polyps with high confidence predictions can achieve high levels of accuracy. Increasing the rates of high confidence optical diagnosis can improve the clinical application of real-time optical diagnosis in routine practice. The primary aim of this prospective study was to evaluate whether high magnifying endoscopy improves the rates of high confidence narrow-band imaging (NBI) - based optical diagnosis for differentiating between neoplastic and non-neoplastic colorectal lesions according to the NBI international colorectal endoscopic (NICE) classification. Patients and methods: Consecutive adult patients undergoing colonoscopy with a high magnifying (maximum, $\times 80$ ) colonoscope between April and August 2012 were recruited. The optical diagnosis for each polyp was evaluated during colonoscopy in two consecutive stages by the same endoscopist, who first used NBI with non-magnifying endoscopy (NBI-NME), then NBI with magnifying endoscopy (NBI-ME). A level of confidence was assigned to each prediction.

\section{Introduction}

$\nabla$

Optical endoscopic diagnosis with advanced imaging technology allows the real-time evaluation of polyp histology during colonoscopy. This paradigm avoids the unnecessary resection of diminutive $(\leq 5 \mathrm{~mm})$ hyperplastic polyps in the rectosigmoid colon and the costly evaluation via formal histopathology of diminutive adenomas, which rarely have malignant potential [ 1 -5]. The American Society for Gastrointestinal Endoscopy (ASGE) has proposed key thresholds in its Preservation and Incorporation of Valuable Endoscopic Innovation (PIVI) statement for the real-time endoscopic assessment of diminutive colorectal polyps: a negative predictive value of $90 \%$ or higher and an agreement rate higher than $90 \%$ in determining post-polypectomy surveillance intervals [3].
Results: The analysis included 124 patients (mean age, 56.4 years; male-to-female ratio, $72: 52$ ) with 248 polyps smaller than $10 \mathrm{~mm}$. Of the 248 polyps, 210 were 1 to $5 \mathrm{~mm}$ in size and 38 were 6 to $9 \mathrm{~mm}$ in size; 77 polyps were hyperplastic, 4 were sessile serrated adenomas/polyps, 160 were low grade adenomas, 5 were high grade adenomas, and 2 were deep submucosal invasive carcinomas. The rate of high confidence optical diagnosis when NBI-ME was used was significantly higher than the rate when NBI-NME was used for diminutive ( $1-5 \mathrm{~mm}$ ) polyps ( $92.9 \%$ vs $79.5 \%$, $P<0.001)$ and for small $(6-9 \mathrm{~mm})$ polyps $(94.7 \%$ vs $84.2 \%, P=0.048$ ).

Conclusion: High magnifying endoscopy significantly improved the rates of high confidence NBI-based optical diagnosis of diminutive and small colorectal polyps.

Study registration: UMIN 000007608

A previous report has indicated that high confidence optical diagnosis with narrow-band imaging (NBI) allows expert endoscopists to reach the PIVI thresholds [2]. However, these thresholds have not been met by community gastroenterologists [6]. It has also been reported that rates of high confidence NBI-based optical diagnosis during real-time colonoscopy without magnification are $75 \%$ to $80 \%[2,7]$. Therefore, increasing the rates of high confidence NBI-based optical diagnosis may improve real-time optical diagnosis in vivo and allow the adoption of this technique in routine clinical practice.

We aimed to evaluate whether high magnifying endoscopy improves the rates of high confidence NBI-based optical diagnosis without magnification for differentiating between neoplastic and non-neoplastic colorectal lesions. 


\section{Patients}

$\nabla$

Consecutive adult patients younger than 70 years of age who were scheduled to undergo colonoscopy with a magnifying colonoscope between April and August 2012 were eligible for this study. Exclusion criteria were as follows: (1) patients only with polyps $11 \mathrm{~mm}$ or larger; (2) patients with multiple (>10) polyps (for ethical reasons, given the longer examination time); (3) patients without polyps or whose polyp histopathology had not been evaluated; (4) patients with poor bowel preparation, melanosis, or a history of inflammatory bowel disease, hereditary polyposis syndrome, or Lynch syndrome. Written informed consent was obtained from all patients before the examination. The study protocol was approved by the institutional review board of Sano Hospital (SH011 - 2012), Kobe, Japan, and registered with a clinical trial registry (UMIN 000007608).

\section{Materials and methods}

\section{$\nabla$}

The procedures were done by five endoscopists: two (Y.S. and M. I.) specialists in colonoscopy (SCs) who have extensive experience in magnifying colonoscopy with NBI (>1000 cases) and three (W.S., S.H., and N.H.) general endoscopists (GEs) who have limited experience in magnifying colonoscopy with NBI $(\leq 1000$

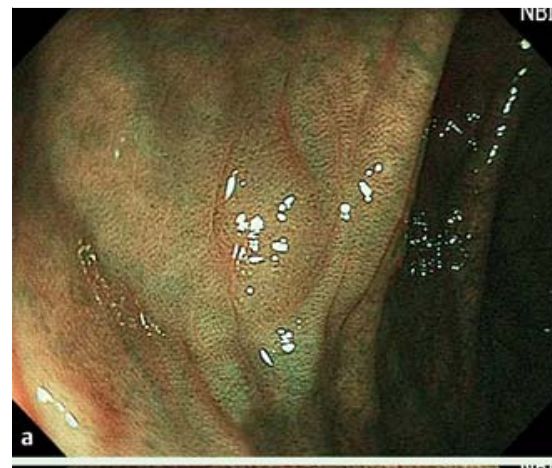

Fig. 1 Flat-type lesion (0-lla), $5 \mathrm{~mm}$ in size. A flat, light brown lesion, which was classified as NICE 2 (narrowband imaging international colorectal endoscopic [classification]) with low confidence prediction by NBI-NME (narrow-band imaging with non-magnifying endoscopy) (a) and

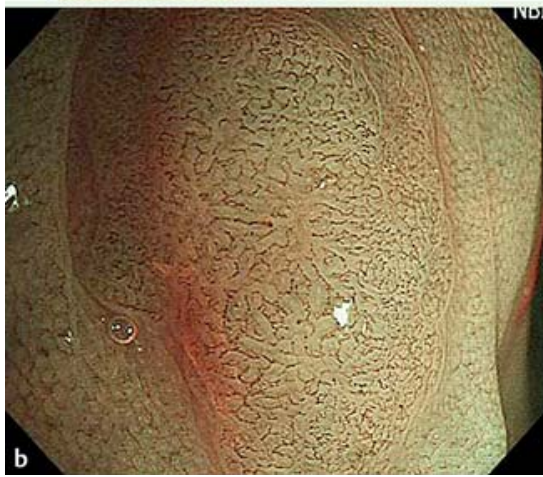
subsequently as NICE 2 with high confidence prediction by NBI-ME (narrow-band imaging with magnifying endoscopy) (b). High magnifying endoscopy revealed the vascular pattern clearly. Histology revealed a tubular adenoma with low grade dysplasia.
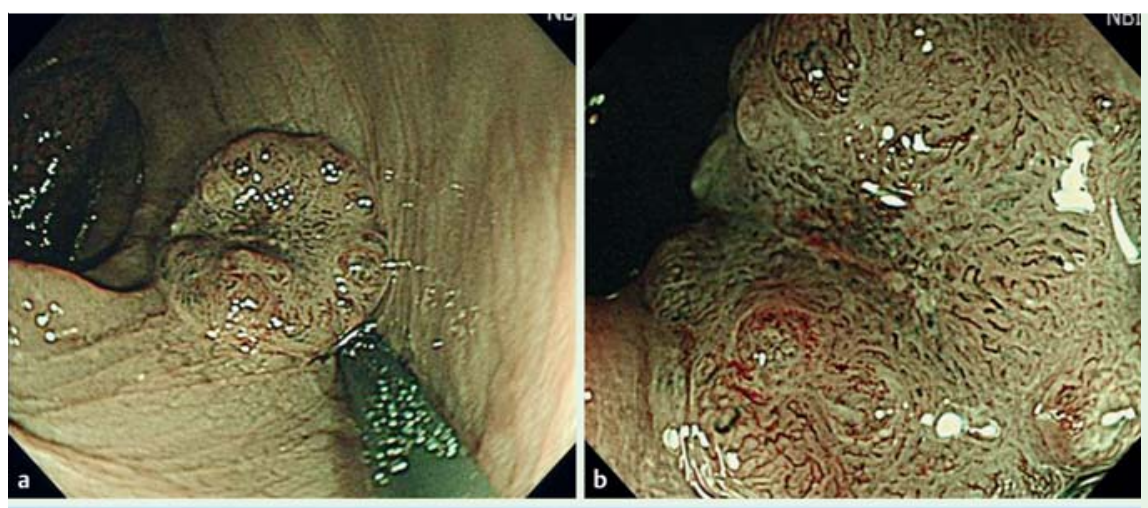

Fig. 2 Depressed-type lesion (0 - Ila + IIc), $8 \mathrm{~mm}$ in size. The lesion had a deeply depressed area with a non-traumatic tube whose diameter was $2.5 \mathrm{~mm}$, which was classified as NICE 3 (narrow-band imaging international colorectal endoscopic [classification]) with high confidence by NBI-NME (narrowband imaging with non-magnifying endoscopy) (a) and NBI-ME (narrow-band imaging with magnifying endoscopy) (b). High magnifying endoscopy revealed the interruption of thick vessels. The endoscopists chose to treat with surgery without endoscopic resection. Histology revealed a moderately differentiated tubular adenocarcinoma invading the deep submucosa (c).

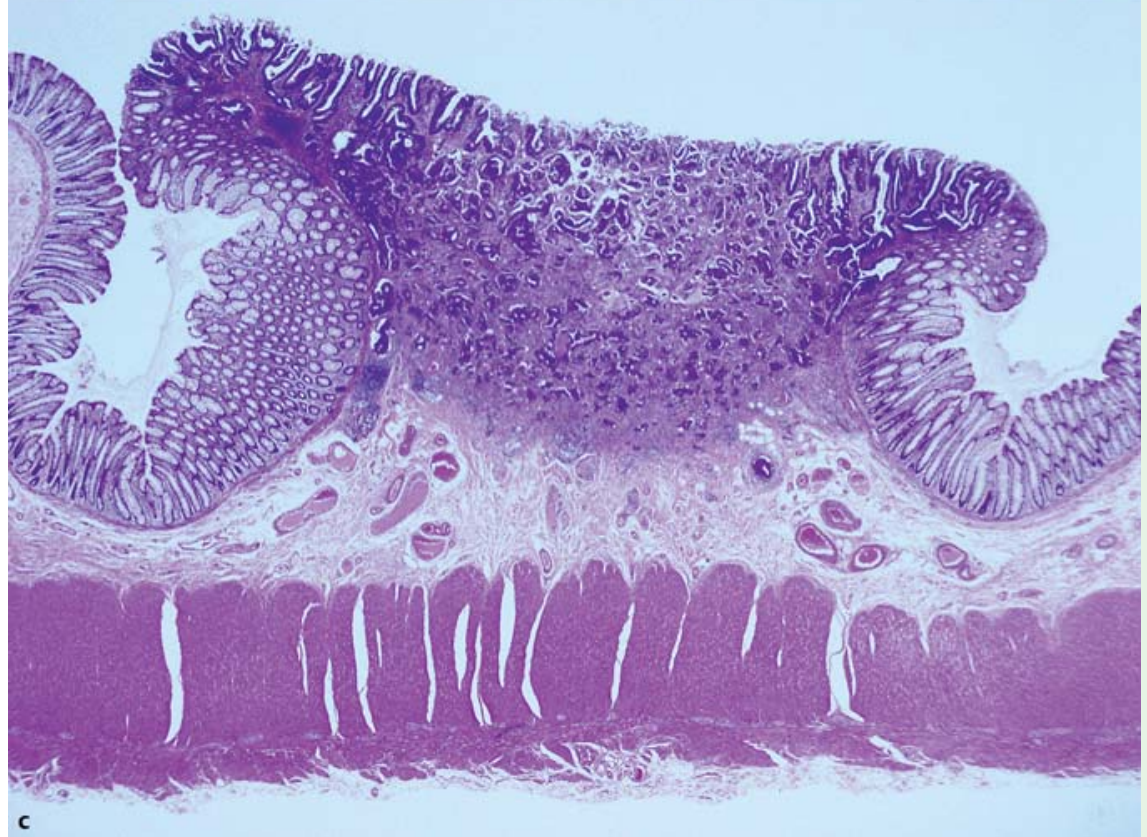


cases) [1]. All five endoscopists were familiar with the NBI international colorectal endoscopic (NICE) classification [7,8]. Magnifying colonoscopes (H260AZI; maximum, $\times 80$ optical zoom; Olympus, Tokyo, Japan) with LUCERA video processors (Olympus) and high definition monitors were used for all procedures. All polyps detected by white light imaging during colonoscopy were washed intensively and examined in two stages, first by NBI with non-magnifying endoscopy (NBI-NME) and subsequently by NBI with high magnifying endoscopy (NBI-ME). The location, size, and shape (Paris classification) of all polyps were recorded [9]. The size was estimated with biopsy forceps (2.2 $\mathrm{mm}$ closed; EndoJaw, Olympus) or polypectomy snare $(10 \mathrm{~mm}$ open; Dragonare S, Xemex, Tokyo, Japan). The endoscopists were asked to indicate polyp type with the NICE classification (NICE 1, non-neoplastic lesion; NICE 2, adenoma; NICE 3, deep submucosal invasive carcinoma) and assign their level of confidence (high or low) to the prediction ( $\bullet$ Fig. 1 and $\bullet$ Fig. 2 ) [2, 7]. The endoscopists made a prediction with high confidence when they were $90 \%$ certain of the diagnosis [7]. The diagnosis at each stage was recorded by an independent observer, who did not allow the prediction to be changed at subsequent steps.

All polyps in the prospective study were resected or biopsied for histopathologic evaluation as the reference standard. Multiple hyperplastic polyps $5 \mathrm{~mm}$ or smaller in the rectum and sigmoid colon were biopsied. An experienced gastrointestinal histopathologist (T.F.), who was blinded to the endoscopic diagnosis, classified all specimens according to the World Health Organization classification [10]. Lesions identified histopathologically as adenoma, traditional serrated adenoma, or carcinoma were classified as neoplastic lesions; others, including hyperplastic polyps, were classified as non-neoplastic lesions. We classified sessile serrated adenomas/polyps as non-neoplastic lesions because endoscopic criteria to distinguish sessile serrated adenomas/ polyps from hyperplastic polyps or a pathologic gold standard for diagnosis has not been fully established.

\section{Statistical analysis}

To detect a significant difference between a high confidence rate of $90 \%$ with NBI-ME and an $80 \%$ rate with NBI-NME $[2,11]$, with a two-sided $5 \%$ significance level and $80 \%$ power with McNemar's test, a sample size of 250 consecutive polyps was required. We used McNemar's test for the paired analysis of categorical variables to compare rates of high confidence optical diagnosis with NBI-ME and rates with NBI-NME. Secondary analysis was performed with the chi-squared test. A two-sided $P$ value of less than 0.05 was considered statistically significant. We followed the STROBE (STrengthening the Reporting of OBservational studies in Epidemiology) guidelines in reporting our findings [12].

\section{Results}

$\nabla$

Of the 329 patients invited to participate, 124 patients with 248 polyps $(<10 \mathrm{~mm})$ were analyzed prospectively $(\bullet$ Fig. 3$)$. All participants underwent total colonoscopy to the cecum. The SCs performed 44 colonoscopies and detected 85 polyps; the GEs performed 80 colonoscopies and detected 163 polyps. The polyp detection rates per procedure were $1.9(85 / 44)$ for the SCs and 2.0 $(163 / 80)$ for the GEs. There was no significant difference between the two groups.

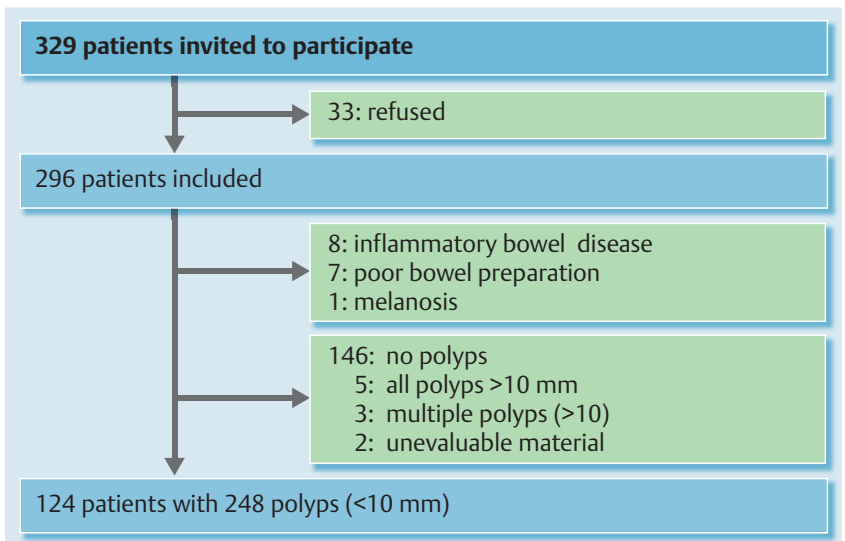

Fig. 3 Patient flow chart.

\section{Clinicopathologic features}

The characteristics of the eligible patients and resected polyps are shown in $\odot$ Table 1 . Of the 248 polyps, 210 were diminutive $(\leq 5 \mathrm{~mm})$ polyps and 38 were small $(6-9 \mathrm{~mm})$ polyps. The macroscopic shapes (Paris classification) of the lesions were 80 protruded ( 0 - Is, Ip), 166 flat ( 0 - IIa), and 2 depressed ( 0 - IIc).

Histopathologically, 77 were hyperplastic polyps, 4 were sessile serrated adenomas/polyps, 160 were low grade adenomas, 5 were high grade adenomas, and 2 were deep submucosal invasive carcinomas. Both of the deep submucosal invasive carcinomas were depressed, and both were small. None of the diminutive adenomas had villous components or high grade dysplasia.

\section{Rates of high confidence optical diagnosis}

- Table 2 and $\odot$ Table 3 show the rates of high confidence optical diagnosis with NBI-NME and NBI-ME. A significantly higher percentage of the 248 polyps was predicted with high confidence by NBI-ME $(93.1 \%, \mathrm{n}=231)$ than by NBI-NME $(80.2 \%, \mathrm{n}=199 ; P<$ 0.001 , McNemar's test). When the polyps were stratified by size, magnifying endoscopy significantly increased the rates of high confidence optical diagnosis of diminutive polyps $(P<0.001$, McNemar's test) and small polyps ( $P=0.048$, McNemar's test).

Performance characteristics with the level of confidence The performance characteristics of NBI-based optical diagnosis with high and low confidence are shown in $\bullet$ Table 4. For small polyps predicted with high confidence, high levels of accuracy and negative predictive value were achieved $(\geq 90 \%)$ with both NBI-NME and NBI-ME. However, for diminutive polyps predicted

Table 1 Characteristics of the eligible patients and resected polyps.

\begin{tabular}{|l|l|}
\hline Total patients, $\mathrm{n}$ & 124 \\
\hline Male/female & $72 / 52$ \\
\hline Mean age, y (SD) & $56.4(8.7)$ \\
\hline Polyps, $1-5 \mathrm{~mm} / 6-9 \mathrm{~mm}$ & $210 / 38$ \\
\hline Mean size, $\mathrm{mm}$ (SD) & $3.7(1.7)$ \\
\hline Location, right side/left side & $128 / 120$ \\
\hline Shape, protruded/flat/depressed & $80 / 166 / 2$ \\
\hline Histopathology, 1 - 5 mm/6-9 mm & $68 / 9$ \\
\hline Hyperplastic polyp & $1 / 3$ \\
\hline Sessile serrated adenoma/polyp & $141 / 19$ \\
\hline Low grade adenoma & $0 / 5$ \\
\hline High grade adenoma & $0 / 2$ \\
\hline Deep submucosal invasive carcinoma & \\
\hline
\end{tabular}


Table 2 Rates of high confidence optical diagnosis with NBI-NME and NBIME.

\begin{tabular}{|llll|}
\hline & NBI-NME & NBI-ME & P value* $^{*}$ \\
\hline All sizes $(1-9 \mathrm{~mm})$ & $\begin{array}{l}80.2 \% \\
(199 / 248)\end{array}$ & $93.1 \%$ & $<0.001$ \\
& $\begin{array}{l}(231 / 248) \\
19.5 \%\end{array}$ & $92.9 \%$ & $<0.001$ \\
& $(167 / 210)$ & $(195 / 210)$ & \\
\hline $6-9 \mathrm{~mm}$ & $\begin{array}{l}84.2 \% \\
(32 / 38)\end{array}$ & $94.7 \%$ & 0.048 \\
\hline
\end{tabular}

NBI-NME, narrow-band imaging with non-magnifying endoscopy; NBI-ME, narrowband imaging with magnifying endoscopy.

* McNemar's test.

with high confidence, the level of accuracy was substantially lower with both NBI-NME and NBI-ME, and the negative predictive values did not reach the ASGE-recommended threshold of $90 \%$. There were no significant differences in performance characteristics between NBI-NME and NBI-ME for diminutive polyps or small polyps.

- Table 3 shows the effects of NBI-ME on the levels of confidence with accuracy by NBI-NME. Of the 43 diminutive polyps initially predicted with low confidence (and accuracy of $58.1 \%$ ) by NBINME, 31 (72.1\%) were subsequently predicted with high confidence and a higher accuracy of $77.4 \%$ by NBI-ME. Similarly, of the 6 small polyps initially predicted with low confidence (and accuracy of $66.7 \%$ ) by NBI-NME, 4 (66.7\%) were predicted with high confidence and a higher accuracy of $75.0 \%$ by NBI-ME. However, these improvements in accuracy with NBI-ME were not statistically significant in the case of either the diminutive $(P=0.09$, chi-squared test) or the small polyps ( $P=0.83$, chi-squared test).

\section{Differences between performance characteristics of specialists in colonoscopy and those of general endoscopists}

- Table 5 presents a subgroup analysis of the performance characteristics of endoscopists with varying levels of NBI experience for predictions made with high confidence. For diminutive polyps, the SCs (> 1000 cases of magnifying NBI) achieved accuracy rates $(90.1 \%$ and $90.7 \%)$ and negative predictive values $(88.9 \%$ and $90.9 \%$ ) that for the most part reached the ASGE-recommended threshold of $90 \%$. In comparison, the GEs (with minimal magnifying NBI experience) achieved lower accuracy rates (82.3 $\%$ ) and negative predictive values (71.4\%), and they failed to reach the $90 \%$ threshold. The only significant difference between the performance characteristics of the SCs and those of the GEs was in the specificity for diminutive polyps; the SCs achieved higher specificity rates with both NBI-NME (87.0\% vs $51.7 \% ; P=0.007$, chi-squared test) and NBI-ME (85.7\% vs $58.8 \% ; P=0.02$, chisquared test).

\section{Discussion}

In this study, we demonstrated that high magnifying endoscopy significantly improved the rates of high confidence NBI-based optical diagnosis for differentiating between neoplastic and non-neoplastic colorectal lesions. To our knowledge, this is the first study to show a benefit of high magnifying endoscopy for improving the rates of high confidence optical diagnosis.

Approximately $70 \%$ of the polyps originally predicted with low confidence by NBI-NME were predicted with high confidence by NBI-ME. Furthermore, the rate of high confidence predictions for almost all polyps $(98 \%-100 \%)$ predicted with NBI-NME was maintained with NBI-ME. We did not show any significant benefit of NBI-ME over NBI-NME for improving the performance characteristics of optical diagnosis made with high confidence; however, dramatic differences between the performance characteristics of high confidence predictions by NBI-ME and those of low confidence predictions by NBI-NME were evident. Our results indicate that NBI-ME should be applied when the optical diagnosis without magnification cannot be made with high confidence, especially in the case of diminutive polyps.

Our results also demonstrated the impact of NBI experience on the performance characteristics of optical diagnosis for diminutive polyps. We defined an SC as someone with experience in more than 1000 cases of magnifying NBI on the basis of a study in which NBI experts were defined as those who had performed NBI colonoscopy procedures more than 1000 times [1]. For small polyps, both the SCs and GEs achieved high levels of accuracy and negative predictive values. However, for diminutive polyps, only the SCs achieved the ASGE-recommended threshold levels for accuracy and negative predictive value. In comparison, the GEs achieved lower levels of accuracy and negative predictive value, in accordance with previous reports $[1,6,13]$. Furthermore, a significant difference between the performance characteristics of the two groups was seen in the specificity rates for the diagnosis of diminutive polyps (despite limitations in the study power for such analyses). This finding suggests that the GEs, in comparison with the SCs, were not able to diagnose diminutive hyperplastic polyps accurately. The $40 \%$ difference between the specificity rates for the diagnosis of small polyps of the two groups did not reach statistical significance.

This study had some limitations. First, it may not be possible to generalize our results to community practice because optical high magnification has not been widely used, particularly in Western countries [14]. However, magnifying endoscopes providing high level optical magnification have only recently become routinely available outside Japan, may shorten the learning curve, and may allow a more widespread dissemination of magnification-based optical diagnosis in routine practice $[15,16]$. Second, considering the use of magnifying endoscopy in daily clinical practice, we did not employ a randomized study design

Table 3 Effect of NBI-ME on level of confidence with accuracy by NBI-NME.

\begin{tabular}{|c|c|c|c|c|c|c|c|c|c|c|c|c|}
\hline & \multicolumn{4}{|c|}{ All sizes (1-9mm) } & \multicolumn{4}{|l|}{$1-5 \mathrm{~mm}$} & \multicolumn{4}{|c|}{$6-9 \mathrm{~mm}$} \\
\hline NBI-NME & \multicolumn{2}{|c|}{$H C(n=199)$} & \multicolumn{2}{|c|}{ LC $(n=49)$} & \multicolumn{2}{|c|}{$H C(n=167)$} & \multicolumn{2}{|c|}{ LC $(n=43)$} & \multicolumn{2}{|c|}{$\mathrm{HC}(\mathrm{n}=32)$} & \multicolumn{2}{|c|}{$L C(n=6)$} \\
\hline Accuracy & $86.4 \%$ & & $59.2 \%$ & & $85.0 \%$ & & $58.1 \%$ & & $93.8 \%$ & & $66.7 \%$ & \\
\hline NBI-ME & $\begin{array}{l}\mathrm{HC} \\
(n=196)\end{array}$ & $\begin{array}{l}\mathrm{LC} \\
(n=3)\end{array}$ & $\begin{array}{l}H C \\
(n=35)\end{array}$ & $\begin{array}{l}\text { LC } \\
(n=14)\end{array}$ & $\begin{array}{l}\mathrm{HC} \\
(n=164)\end{array}$ & $\begin{array}{l}\mathrm{LC} \\
(n=3)\end{array}$ & $\begin{array}{l}\mathrm{HC} \\
(n=31)\end{array}$ & $\begin{array}{l}\mathrm{LC} \\
(n=12)\end{array}$ & $\begin{array}{l}\mathrm{HC} \\
(n=32)\end{array}$ & $\begin{array}{l}\text { LC } \\
(n=0)\end{array}$ & $\begin{array}{l}\mathrm{HC} \\
(n=4)\end{array}$ & $\begin{array}{l}\text { LC } \\
(n=2)\end{array}$ \\
\hline Accuracy & $88.3 \%$ & $33.3 \%$ & $77.1 \%$ & $50.0 \%$ & $86.6 \%$ & $33.3 \%$ & $77.4 \%$ & $50.0 \%$ & $96.9 \%$ & - & $75.0 \%$ & $50.0 \%$ \\
\hline
\end{tabular}

NBI-ME, narrow-band imaging with magnifying endoscopy; NBI-NME, narrow-band imaging with non-magnifying endoscopy; HC, high confidence; LC, low confidence. 
Originaticicos

Table 4 Performance characteristics of NBI-NME and NBI-ME with levels of confidence.

\begin{tabular}{|c|c|c|c|c|c|}
\hline & \multirow[t]{2}{*}{$\mathrm{HC} / \mathrm{LC}$} & \multicolumn{2}{|l|}{$1-5 \mathrm{~mm}$} & \multicolumn{2}{|l|}{$6-9 \mathrm{~mm}$} \\
\hline & & NBI-NME & NBI-ME & NBI-NME & NBI-ME \\
\hline \multirow[t]{3}{*}{ Accuracy } & $\mathrm{HC}$ & $\begin{array}{l}85.0 \% \\
(142 / 167)\end{array}$ & $\begin{array}{l}85.1 \% \\
(166 / 195)\end{array}$ & $\begin{array}{l}93.8 \% \\
(30 / 32)\end{array}$ & $\begin{array}{l}94.4 \% \\
(34 / 36)\end{array}$ \\
\hline & LC & $\begin{array}{l}58.1 \% \\
(25 / 43)\end{array}$ & $\begin{array}{l}46.7 \% \\
(7 / 15)\end{array}$ & $\begin{array}{l}66.7 \% \\
(4 / 6)\end{array}$ & $\begin{array}{l}50.0 \% \\
(1 / 2)\end{array}$ \\
\hline & All & $\begin{array}{l}79.5 \% \\
(167 / 210)\end{array}$ & $\begin{array}{l}82.4 \% \\
(173 / 210)\end{array}$ & $\begin{array}{l}89.5 \% \\
(34 / 38)\end{array}$ & $\begin{array}{l}92.1 \% \\
(35 / 38)\end{array}$ \\
\hline \multirow[t]{3}{*}{ Sensitivity } & $\mathrm{HC}$ & $\begin{array}{l}93.0 \% \\
(107 / 115)\end{array}$ & $\begin{array}{l}91.7 \% \\
(122 / 133)\end{array}$ & $\begin{array}{l}100 \% \\
(24 / 24)\end{array}$ & $\begin{array}{l}100 \% \\
(26 / 26)\end{array}$ \\
\hline & LC & $\begin{array}{l}61.5 \% \\
(16 / 26)\end{array}$ & $\begin{array}{l}62.5 \% \\
(5 / 8)\end{array}$ & $\begin{array}{l}100 \% \\
(2 / 2)\end{array}$ & $\begin{array}{l}- \\
(0 / 0)\end{array}$ \\
\hline & All & $\begin{array}{l}87.2 \% \\
(123 / 141)\end{array}$ & $\begin{array}{l}90.1 \% \\
(127 / 141)\end{array}$ & $\begin{array}{l}100 \% \\
(26 / 26)\end{array}$ & $\begin{array}{l}100 \% \\
(26 / 26)\end{array}$ \\
\hline \multirow[t]{3}{*}{ Specificity } & $\mathrm{HC}$ & $\begin{array}{l}67.3 \% \\
(35 / 52)\end{array}$ & $\begin{array}{l}71.0 \% \\
(44 / 62)\end{array}$ & $\begin{array}{l}75.0 \% \\
(6 / 8)\end{array}$ & $\begin{array}{l}80.0 \% \\
(8 / 10)\end{array}$ \\
\hline & LC & $\begin{array}{l}52.9 \% \\
(9 / 17)\end{array}$ & $\begin{array}{l}28.6 \% \\
(2 / 7)\end{array}$ & $\begin{array}{l}50.0 \% \\
(2 / 4)\end{array}$ & $\begin{array}{l}50.0 \% \\
(1 / 2)\end{array}$ \\
\hline & All & $\begin{array}{l}63.8 \% \\
(44 / 69)\end{array}$ & $\begin{array}{l}66.7 \% \\
(46 / 69)\end{array}$ & $\begin{array}{l}66.7 \% \\
(8 / 12)\end{array}$ & $\begin{array}{l}75.0 \% \\
(9 / 12)\end{array}$ \\
\hline \multirow[t]{3}{*}{ Positive predictive value } & $\mathrm{HC}$ & $\begin{array}{l}86.3 \% \\
(107 / 124)\end{array}$ & $\begin{array}{l}87.1 \% \\
(122 / 140)\end{array}$ & $\begin{array}{l}92.3 \% \\
(24 / 26)\end{array}$ & $\begin{array}{l}92.9 \% \\
(26 / 28)\end{array}$ \\
\hline & LC & $\begin{array}{l}66.7 \% \\
(16 / 24)\end{array}$ & $\begin{array}{l}50.0 \% \\
(5 / 10)\end{array}$ & $\begin{array}{l}50.0 \% \\
(2 / 4)\end{array}$ & $\begin{array}{l}0 \% \\
(0 / 1)\end{array}$ \\
\hline & All & $\begin{array}{l}83.1 \% \\
(123 / 148)\end{array}$ & $\begin{array}{l}84.7 \% \\
(127 / 150)\end{array}$ & $\begin{array}{l}86.7 \% \\
(26 / 30)\end{array}$ & $\begin{array}{l}89.7 \% \\
(26 / 29)\end{array}$ \\
\hline \multirow[t]{3}{*}{ Negative predictive value } & $\mathrm{HC}$ & $\begin{array}{l}81.4 \% \\
(35 / 43)\end{array}$ & $\begin{array}{l}80.0 \% \\
(44 / 55)\end{array}$ & $\begin{array}{l}100 \% \\
(6 / 6)\end{array}$ & $\begin{array}{l}100 \% \\
(8 / 8)\end{array}$ \\
\hline & LC & $\begin{array}{l}47.4 \% \\
(9 / 19)\end{array}$ & $\begin{array}{l}40.0 \% \\
(2 / 5)\end{array}$ & $\begin{array}{l}100 \% \\
(2 / 2)\end{array}$ & $\begin{array}{l}100 \% \\
(1 / 1)\end{array}$ \\
\hline & All & $\begin{array}{l}71.0 \% \\
(44 / 62)\end{array}$ & $\begin{array}{l}76.7 \% \\
(46 / 60)\end{array}$ & $\begin{array}{l}100 \% \\
(8 / 8)\end{array}$ & $\begin{array}{l}100 \% \\
(9 / 9)\end{array}$ \\
\hline
\end{tabular}

NBI-NME, narrow-band imaging with non-magnifying endoscopy; NBI-ME, narrow-band imaging with magnifying endoscopy; HC, high confidence; LC, low confidence; All, HC + LC.

Table 5 Comparison of the performance characteristics of high confidence optical diagnosis by specialists in colonoscopy and by general endoscopists.

\begin{tabular}{|c|c|c|c|c|c|}
\hline & \multirow[t]{2}{*}{ SCs/GEs } & \multicolumn{2}{|l|}{$1-5 \mathrm{~mm}$} & \multicolumn{2}{|l|}{$6-9 \mathrm{~mm}$} \\
\hline & & NBI-NME & NBI-ME & NBI-NME & NBI-ME \\
\hline \multirow[t]{2}{*}{ Accuracy } & SCs & $\begin{array}{l}90.7 \% \\
(49 / 54)\end{array}$ & $\begin{array}{l}90.1 \% \\
(64 / 71)\end{array}$ & $\begin{array}{l}100 \% \\
(8 / 8)\end{array}$ & $\begin{array}{l}100 \% \\
(10 / 10)\end{array}$ \\
\hline & GEs & $\begin{array}{l}82.3 \% \\
(93 / 113)\end{array}$ & $\begin{array}{l}82.3 \% \\
(102 / 124)\end{array}$ & $\begin{array}{l}91.7 \% \\
(22 / 24)\end{array}$ & $\begin{array}{l}92.3 \% \\
(24 / 26)\end{array}$ \\
\hline \multirow[t]{2}{*}{ Sensitivity } & SCs & $\begin{array}{l}93.5 \% \\
(29 / 31)\end{array}$ & $\begin{array}{l}93.0 \% \\
(40 / 43)\end{array}$ & $\begin{array}{l}100 \% \\
(4 / 4)\end{array}$ & $\begin{array}{l}100 \% \\
(5 / 5)\end{array}$ \\
\hline & GEs & $\begin{array}{l}92.9 \% \\
(78 / 84)\end{array}$ & $\begin{array}{l}91.1 \% \\
(82 / 90)\end{array}$ & $\begin{array}{l}100 \% \\
(20 / 20)\end{array}$ & $\begin{array}{l}100 \% \\
(21 / 21)\end{array}$ \\
\hline \multirow[t]{2}{*}{ Specificity } & SCs & $\begin{array}{l}87.0 \%^{1} \\
(20 / 23)\end{array}$ & $\begin{array}{l}85.7 \%^{2} \\
(24 / 28)\end{array}$ & $\begin{array}{l}100 \% \\
(4 / 4)\end{array}$ & $\begin{array}{l}100 \% \\
(5 / 5)\end{array}$ \\
\hline & GES & $\begin{array}{l}51.7 \%^{1} \\
(15 / 29)\end{array}$ & $\begin{array}{l}58.8 \%^{2} \\
(20 / 34)\end{array}$ & $\begin{array}{l}50.0 \% \\
(2 / 4)\end{array}$ & $\begin{array}{l}60.0 \% \\
(3 / 5)\end{array}$ \\
\hline \multirow[t]{2}{*}{ Positive predictive value } & SCs & $\begin{array}{l}90.6 \% \\
(29 / 32)\end{array}$ & $\begin{array}{l}90.9 \% \\
(40 / 44)\end{array}$ & $\begin{array}{l}100 \% \\
(4 / 4)\end{array}$ & $\begin{array}{l}100 \% \\
(5 / 5)\end{array}$ \\
\hline & GEs & $\begin{array}{l}84.8 \% \\
(78 / 92)\end{array}$ & $\begin{array}{l}85.4 \% \\
(82 / 96)\end{array}$ & $\begin{array}{l}90.9 \% \\
(20 / 22)\end{array}$ & $\begin{array}{l}91.3 \% \\
(21 / 23)\end{array}$ \\
\hline \multirow[t]{2}{*}{ Negative predictive value } & SCs & $\begin{array}{l}90.9 \% \\
(20 / 22)\end{array}$ & $\begin{array}{l}88.9 \% \\
(24 / 27)\end{array}$ & $\begin{array}{l}100 \% \\
(4 / 4)\end{array}$ & $\begin{array}{l}100 \% \\
(5 / 5)\end{array}$ \\
\hline & GES & $\begin{array}{l}71.4 \% \\
(15 / 21)\end{array}$ & $\begin{array}{l}71.4 \% \\
(20 / 28)\end{array}$ & $\begin{array}{l}100 \% \\
(2 / 2)\end{array}$ & $\begin{array}{l}100 \% \\
(3 / 3)\end{array}$ \\
\hline
\end{tabular}

NBI-NME, narrow-band imaging with non-magnifying endoscopy; NBI-ME, narrow-band imaging with magnifying endoscopy; SCs, specialists in colonoscopy; GEs, general endoscopists.

The differences between the specificity rates for the SC group and the specificity rates for the GE group were significant.

$1 P=0.007$

$2 P=0.02$ 
because we preferred to evaluate the confidence rates of high magnifying endoscopy after the application of non-magnifying endoscopy. In fact, we usually use NBI without magnification initially to diagnose a polyp and evaluate its entire shape, vascularity, surface pattern, and color. In clinical practice, we then apply NBI with magnification to evaluate local findings in detail. If we had employed a randomized design (NBI-ME vs NBI-NME), NBIME would have been used without NBI-NME, which is not at all the situation in daily clinical practice. Third, the instruments used in this study (H260AZI and LUCERA video processor) are available only in the United Kingdom, Japan, and Asia. Finally, our study was performed in a single, non-academic center. Additional, multicenter studies are needed to confirm our results. In conclusion, high magnifying endoscopy is a promising technique for improving the rates of high confidence NBI-based optical diagnosis for diminutive and small polyps. However, the performance characteristics of the high confidence predictions made by less experienced endoscopists for diminutive polyps, especially diminutive hyperplastic polyps, were not satisfactory. This finding indicates an urgent need of effective and efficient training programs for general endoscopists who wish to apply the NBI-based optical diagnosis of diminutive polyps in routine practice.

\section{Competing interests: None}

\section{Institutions}

${ }^{1}$ Sano Hospital, Gastrointestinal Center, Kobe, Japan

2 Department of Medical Statistics, Toho University, Tokyo, Japan

${ }^{3}$ University of Queensland School of Medicine, Brisbane, Australia

${ }^{4}$ Gastroenterology, Stanford University School of Medicine, Palo Alto, California, USA

${ }^{5}$ Department of Surgical and Molecular Pathology, Dokkyo University School of Medicine, Tochigi, Japan

\section{Acknowledgments}

$\nabla$

The authors thank Mayumi Yamaguchi, Yukie Kuragaki, Naoko Hirota, Mariko Masuda, Saori Miyazaki, Keiko Iwasa, Naoko Fukuda, Youko Taguchi, Sachiko Senou, and Yuko Sakamoto for kindly assisting in this study.

\section{References}

1 Ignjatovic A, East JE, Suzuki $N$ et al. Optical diagnosis of small colorectal polyps at routine colonoscopy (Detect InSpect ChAracterise Resect and Discard; DISCARD trial): a prospective cohort study. Lancet Oncol 2009; 10: $1171-1178$
2 Rex DK. Narrow-band imaging without optical magnification for histologic analysis of colorectal polyps. Gastroenterology 2009; 136: $1174-$ 1181

3 Rex DK, Kahi C, O'Brien M et al. The American Society for Gastrointestinal Endoscopy PIVI (Preservation and Incorporation of Valuable Endoscopic Innovations) on real-time endoscopic assessment of the histology of diminutive colorectal polyps. Gastrointest Endosc 2011; 73: 419-422

4 Hassan C, Pickhardt PJ, Rex DK. A resect and discard strategy would improve cost-effectiveness of colorectal cancer screening. Clin Gastroenterol Hepatol 2010; 8: 865-869

5 Kessler WR, Imperiale TF, Klein RW et al. A quantitative assessment of the risks and cost savings of forgoing histologic examination of diminutive polyps. Endoscopy 2011; 43: 683-691

6 Ladabaum U, Fioritto A, Mitani A et al. Real-time optical biopsy of colon polyps with narrow band imaging in community practice does not yet meet key thresholds for clinical decisions. Gastroenterology 2013; 144: $81-91$

7 Hewett DG, Kaltenbach T, Sano Y et al. Validation of a simple classification system for endoscopic diagnosis of small colorectal polyps using narrow-band imaging. Gastroenterology 2012; 143: 599-607

8 Hayashi N, Tanaka S, Hewett DG et al. Endoscopic prediction of deep submucosal invasive carcinoma: validation of the Narrow-Band Imaging International Colorectal Endoscopic (NICE) classification. Gastrointest Endosc 2013; 78: 625 -632

9 Paris Workshop Participants. The Paris endoscopic classification of superficial neoplastic lesions: esophagus, stomach, and colon. Gastrointest Endosc 2003; 58: 3-43

10 World Health Organization. World Health Organization classification of tumours of the digestive system. 4th: edn. Lyon, France: IARC Press; 2010

11 Takeuchi $Y$, Hanaoka N, Hanafusa M. Recent advances in diagnostic endoscopy for colorectal neoplasm. In: Pascu O, ed. Gastrointestinal endoscopy. Rijeka: InTech; 2011: DOI 10.5772/21892 Available from: http://www.intechopen.com/books/gastrointestinal-endoscopy/recent-advances-in-diagnostic-endoscopy-for-colorectal-neoplasm Accessed December 12, 2014

12 von Elm E, Altman DG, Egger $M$ et al. The Strengthening the Reporting of Observational Studies in Epidemiology (STROBE) statement: guidelines for reporting observational studies. Lancet 2007; 370: $1453-$ 1457

13 Higashi $R$, Uraoka T, Kato J et al. Diagnostic accuracy of narrow-band imaging and pit pattern analysis significantly improved for less-experienced endoscopists after an expanded training program. Gastrointest Endosc 2010; 72: 127-135

14 Rex DK, Fennerty MB, Sharma P et al. Bringing new endoscopic imaging technology into everyday practice: what is the role of professional GI societies? Polyp imaging as a template for moving endoscopic innovation forward to answer key clinical questions Gastrointest Endosc 2010; 71: $142-146$

15 Iwatate M, Ikumoto T, Hattori S et al. NBI and NBI combined with magnifying colonoscopy. Diagn Ther Endosc 2012: 173269

16 Togashi K, Konishi F, Ishizuka T et al. Efficacy of magnifying endoscopy in the differential diagnosis of neoplastic and non-neoplastic polyps of the large bowel. Dis Colon Rectum 1999; 42: $1602-1608$ 